\title{
Lugares y pasados: repensando los procesos de espacialización de las memorias afro en Argentina
}

Places and pasts: rethinking spatialization process of Afro memories in Argentina

\author{
Paola Carolina Monkevicius paomon@speedy.com.ar \\ https://orcid.org/0000-0003-1234-9747
}

Facultad de Ciencias Naturales y Museo; Universidad Nacional de La Plata/

Consejo Nacional de Investigaciones Científicas y Técnicas (Argentina)

\section{Resumen}

A partir de la visibilización de la presencia de afrodescendientes e inmigrantes africanos en Argentina nos interrogamos sobre el lugar de los procesos de producción de memorias subalternas en tanto proyectos identitarios y políticos. Más específicamente, consideramos que las luchas por reconocimiento e igualdad de derechos se juegan, en gran medida, en el plano de las memorias siendo que la identificación de los sujetos como "afros" requiere de procesos 
de reconstrucción del pasado que unifiquen y legitimen orígenes, trayectorias y, por lo tanto, que autoricen demandas presentes. Para los fines de este artículo exploramos las formas de uso, negociación y apropiación de los espacios históricamente utilizados para fijar, reproducir y transmitir la narrativa oficial por parte del colectivo conformado por afrodescendientes e inmigrantes africanos, instalando así formas de recordación subalternas dentro de o en disputa con la narrativa hegemónica. Para ello contamos con el trabajo etnográfico realizado diversos tipos de encuentros, en particular, los de carácter conmemorativo.

Palabras clave: Memorias; lugares; afrodescendientes; inmigrantes africanos; narrativa hegemónica.

\section{Abstract}

Based on the visibilization of afrodescendants and african migrants in Argentina we inquire about the places of the production process of the subaltern memories as political and identity projects. More specifically, we consider that the disputes for recognition and equality take place, in large part, in memories field being that the identification of the subjects as "Afros" require of the process of the past reconstruction that unify and legitimase origins, trajectories and therefore, that authorize demands in the present. For this paper we explore how Afrodescendants and African inmigrants collective use, negotiate and appropiate of the spaces historically used to fix, reproduce and transmit the official narrative, posicionating ways of subaltern remembering inside of or in dispute to the hegemonic narrative. For this purpose we count on the ethnographic fieldwork made in differents acts, in particular, the conmemorative acts.

Keywords: Memories; places; afrodescendants; african inmigrants; hegemonic narrative.

Pensar la negritud en Argentina implica sumergirse en una problemática que aun gravita entre la idea de la desaparición, con la consecuente ausencia de racismo, y una creciente visibilización de sujetos racializados, cada vez más conscientes de su situación de subalternización. Los estudios académicos han indagado sobre estas dinámicas y tensiones poniendo en suspenso la indiscutida, hasta hace solo un par de décadas, idea de la blanquedad argentina. Más precisamente, esta construcción comienza a mostrar grietas 
cuando a partir de la década de 1990 (re)aparecen en la escena pública afrodescendientes e inmigrantes africanos nucleados en asociaciones y agrupaciones demandando reconocimiento y derechos ciudadanos. Desde nuestro trabajo creemos que estas disputas se libran en gran medida en el terreno de las memorias siendo que la identificación de los sujetos como "afros" requiere de procesos de reconstrucción del pasado que, a la vez que impugnan relatos hegemónicos, unifiquen y legitimen orígenes, trayectorias y, por lo tanto, autoricen demandas presentes. Específicamente, en el desarrollo de esta ponencia, reflexionaremos sobre las nuevas presencias de las memorias afroargentinas y africanas en espacios históricamente utilizados para fijar, reproducir y transmitir la narrativa oficial. Se trata de espacios públicos y estatales donde el olvido y la negación de "otros" pasados ceden lugar a la "restauración" en tanto trabajo político (Ramos, 2017). En particular, prestamos atención a algunos de los espacios gestionados para conmemorar el Día Nacional del Afroargentino desde la sanción de la ley en 2013 a partir del trabajo de campo etnográfico realizado durante estos festejos conmemorativos.

\section{Un contexto blanco para la afrodescendencia}

Como en otros procesos de construcción del estado-nación, en Argentina se puso en marcha un efectivo trabajo de ingeniería cultural tendiente a imaginar la nación y a sus ciudadanos como una indiscutida homogeneidad basada en la blanquedad producto del crisol de razas de origen europeo. Lo que nos interesa destacar es que estas representaciones hegemónicas producen realidades (Segato, 2007: 29) en su lógica de clasificación de los sujetos, esto es, aquellos que pertenecen a la nación y, por lo tanto, ven garantidos sus derechos ciudadanos, y los "otros", los diversos, que no lograron ajustarse al ideal desetnicizado y desracializado y, en consecuencia, ven condicionado su acceso a la ciudadanía. Dentro de este proceso, los sujetos negros, entendidos como representantes máximos de la diferencia, han sido suprimidos ideológicamente de la nación (Segato, 2007: 255), quedando subsumidos a la "desaparición". En palabras de Geler (2010), se constituían así "en una alteridad pre-histórica, es decir una alteridad que no incidía en el desarrollo histórico del país por estar desaparecida". Sin embargo, mientras invisibilizaban al afrodescendiente dentro de la abarcativa blanquedad, las categorías racializadas siguieron operando y circulando demarcando al "negro" de los sectores populares (sin un necesario origen africano) y excluyendo al sujeto fenotípicamente negro en tanto "extranjero" (1). 
Como mencionamos arriba, esta arraigada construcción hegemónica comienza a ser cuestionada por sujetos que visibilizan negritudes tanto desde lo cultural como desde lo político, y tanto a nivel nacional como regional, proceso acentuado por la llegada, primero, de inmigrantes afrolatinoamericanos (como trabajadores culturales) y, posteriormente, de nuevas corrientes migratorias provenientes de países africanos subsaharianos, acompañado por un interés creciente desde el ámbito académico en el marco del surgimiento de narrativas multiculturales (2).

De esta manera se gestan las condiciones para que los afrodescendientes y africanos objeten formas de subjetivación sedimentadas resultado de su no-presencia dentro de una "formación nacional" donde se producen, enmarcadas en espacios y temporalidades, determinadas "formas de ser otro" (Segato, 2007) y, podríamos agregar, determinadas "formas de recordarse como otro" (Monkevicius, 2015). En términos de Pollak (1992), la "coyuntura o período calmo", exitosamente asegurado por la narrativa hegemónica, comienza a replegarse frente a un período de revisión donde las identidades y las memorias dejan de trabajar por sí solas para convertirse en objeto de reflexión y cuestionamiento.

Es decir, la "aparición" de los afrodescendientes luchando por revertir el proceso de invisibilización "confronta las prácticas representacionales hegemónicas de producir y transmitir la otredad racializada" (Geler, 2012). Surgen entonces nuevas formas de representación y autorrepresentación, que apelan al pasado como ámbito privilegiado de legitimidad y autenticidad y, en consecuencia, de autoridad sobre los reclamos contra la opresión racista y por el reconocimiento de derechos. Las memorias se establecen entonces como una arena central de lucha política.

\section{Las memorias y sus emprendedores}

En este punto creemos necesario dar cuenta brevemente de aquello que entendemos por memorias. Ya en trabajos anteriores (Monkevicius, 2015), planteamos la dificultad de pensar en términos de una "memoria negra"(3) en Argentina siendo que estamos ante un colectivo diverso que se auto adscribe apelando a distintas categorizaciones identitarias, por lo tanto, preferimos entender a las memorias de los afrodescendientes y africanos en su pluralidad y heterogeneidad, es decir, como "memorias compartidas, superpuestas, producto de interacciones múltiples, encuadradas en marcos sociales y en relaciones de poder" (Jelin, 2002: 22). En otros términos, se trata de una práctica social producto de procesos subjetivos que se exteriorizan y materializan mediante la interacción dentro de determinados marcos de 
interpretación, dando lugar a reconstrucciones de sentido y significaciones del pasado ancladas cultural e históricamente. Si bien hablamos de una práctica social compartida por un determinado grupo, esto no significa que sea consensuada, sino que se encuentra sujeta a las disputas derivadas de las jerarquizaciones propias de ese entramado social. Es decir, existen actores con mayor poder de decisión sobre qué acontecimientos recordar y transmitir, cuyas trayectorias legitiman su posición de liderazgo en cuanto a la reconstrucción del pasado y a su utilización como herramienta de lucha en el presente. Siguiendo a Jelin (2002: 48), los denominamos "emprendedores de la memoria" por tratarse de sujetos que se involucran en su proyecto y busca comprometer a los demás en la tarea colectiva de decidir y definir cuál es el pasado del grupo y utilizarlo como proyecto político. En otros términos, "encuadran" las memorias (Pollak, 1989), en tanto agentes especializados en el trabajo de selección y solidificación de puntos de referencia que identifican a cierto colectivo al tiempo que demarcan sus fronteras respecto de otros grupos y respecto del relato oficial nacional. Considerando nuestro referente, los emprendedores participan, en mayor o menor medida, dentro de distintas agrupaciones y organizaciones con diversos grados de formalización, desde las asociaciones de inmigrantes africanos hasta agrupaciones afro de carácter político y cultural (4). En muchos casos, son dirigentes reconocidos por el colectivo que realizan un intenso trabajo por la visibilización y reconocimiento de las minorías de origen africano, interactuando con otras organizaciones de la sociedad civil, organismos internacionales y principalmente con el estado argentino desde una posición de subalternidad. El pasado se constituye entonces en un escenario de disputas y negociación, tanto al interior del colectivo como hacia afuera. Y aquí nos interesa retomar (aunque, como advertimos, no se ajuste rigurosamente a nuestro caso), aquello que sostenía Hanchard (2008: 48) cuando afirmaba que el "motivo oculto" de las memorias negras consiste en reclamar en el presente por las inequidades e injusticias sufridas en el pasado, erigiendo a la "memorialización" como parte de un proyecto político más general. En otros términos, preferimos denominar "restauración" a este proceso donde un colectivo subalternizado trabaja sobre el pasado para reponer eventos negados e impugnados por los relatos hegemónicos y reconstruye marcos de interpretación que habiliten proyectos políticos en el presente (Ramos 2017).

Específicamente en la presente ponencia abordaremos las disputas y consensos sobre el pasado cuando se materializan en torno a determinados espacios que deben reconstituirse para anclar nuevas narrativas, en particular, prestaremos atención a los lugares donde históricamente se constituyó, solidificó y transmitió la narrativa nacional. 


\section{Las memorias afro se abren lugar}

En primer término debemos mencionar que las memorias afro carecen de "lugares destacados" (Candau, 2001: 152), es decir, lugares que "casi siempre tienen nombre y que constituyen refugios o referencias perennes percibidos como otros tantos desafíos al tiempo." A pesar de los esfuerzos realizados por activistas y militantes afrodescendientes, particularmente en la Ciudad Autónoma de Buenos Aires y sus alrededores, han desaparecido los últimos vestigios espaciales con gran significación histórica y cultural para el colectivo. Es el caso, por ejemplo, de la Casa Suiza, una institución alquilada por la asociación afroporteña Shimmy Club para organizar bailes (en particular, de "candombe argentino" y "rumba abierta") durante las festividades del carnaval a lo largo del siglo XX, y la cual fue demolida en 2015 luego de una fallida intervención judicial encabezada por vecinos, activistas afrodescendientes y académicos. Para algunos emprendedores, el espacio debía reconvertirse en un lugar de anclaje de las memorias negras en Argentina teniendo en cuenta que no existe aun en el país un museo que específicamente represente sentidos del pasado afro adosados a formas de patrimonialización materiales e inmateriales. Como sostiene Geler (2012) desde una mirada histórica, "esta falta completa de representación afroargentina -en tanto tal- de los museos, es decir, la falta de archivo, debe ponerse en relación con el tipo de discurso e imagen de nación (...) y es análoga al borramiento de lo afro de la historia nacional posterior a 1850". Y responde, como afirma más adelante, "a la imposición de blanquitud y a la necesidad de no generar "dudas" con respecto al propio "color" en un/a espectador/a sujeto/a a un proceso profundo de creación de subjetividad en su diálogo con las instituciones estatales-nacionales" (5).

Como excepción de lugares de patrimonialización afro, aunque se trate de una iniciativa intersectorial, debemos mencionar el programa "Ruta del Esclavo" de la Organización de las Naciones Unidas para la Educación, la Ciencia y la Cultura (UNESCO), que se propuso (en una de sus etapas) explorar las consecuencias del "choque brutal de culturas" a partir de la trata esclavista en Argentina, Uruguay y Paraguay con el objetivo de impulsar investigación científica, inventariar y preservar los lugares y sitios de memoria y promocionar las culturas vivas y las tradiciones orales. (UNESCO, 2010). Los sitios históricos fueron seleccionados según los requerimientos del organismo multilateral con el aval de referentes y asociaciones del colectivo afro en "delicada disputa" (Annecchiarico, 2018). Así se decidió patrimonializar como sitios históricos de los afroargentinos a la Plaza San Martín (barrio de Retiro) y al Parque Lezama (barrio de San Telmo) en la Ciudad Autónoma de Buenos Aires, la "Capilla de la negros" situada en la provincia de Buenos Aires, y a las estancias jesuíticas de Alta Gracia, en la provincia de Córdoba. Si bien estos espacios son considerados por los afrodescendientes 
como enclaves históricos relevantes, constituyéndose en sedes de diversos encuentros, debemos destacar que la iniciativa del organismo multilateral no los "convierte" per se en lugares de memoria, o sea, lugares donde el colectivo afro trabaje sobre su pasado, inscribiendo sentidos de acuerdo a demandas en el presente. Aunque, según algunos de los impulsores del proyecto, se entiende como puntapié para impulsar otras acciones por parte de las organizaciones (Annecchiarico, 2018).

Tampoco podemos definir a las sedes asociativas que agrupan a los africanos y afrodescendientes como "lugares destacados" de la memoria. En primer lugar, se debe tener en cuenta que son pocas las asociaciones y entidades afro que cuentan con espacios físicos donde realizar actividades sociales, culturales y administrativas (6), entre ellas se encuentran las históricas asociaciones caboverdeanas de ayuda mutua fundadas en las primeras décadas del siglo XX (7), y algunas más recientes que agrupan a afrodescendientes, como por ejemplo, la sede de la DIAFAR (Diáspora Africana de la Argentina) o la perteneciente a Misibamba (que reúne a afroargentinos del tronco colonial). Allí la memoria se instala de manera provisoria a partir de una reconstrucción articulada principalmente por los dirigentes asociativos en actos conmemorativos, artísticos y culturales, en homenajes, dictado de cursos, etcétera.

Por lo anterior y debido a los objetivos de esta ponencia decidimos centrarnos sobre aquellos espacios "externos" al colectivo afrodescendiente, por ejemplo, los museos nacionales, los ámbitos académicos, los centros culturales, los espacios gubernamentales, los públicos, entre otros. Como señala Alonso (1994), la mayoría de estos espacios pueden ser entendidos como una forma de "inscripción cultural" de la idea de estado, que separa los significados hegemónicos de sus inmediatas circunstancias de creación y los concretiza en lugares centrales en los cuales se asigna la unidad de la nación mientras relega los sentidos subalternos (de otros étnico-raciales) a los márgenes. Lo que nos interesa destacar es cómo todos estos lugares mencionados, que actuaron y aun actúan como condensadores de sentidos sobre la historia nacional, son reapropiados por determinados sectores del colectivo afro para situar otras lecturas del pasado que ahora se "oficializan" y pasan a formar parte del saber público (Draper, 2011).

Particularmente nos detendremos sobre algunos de los lugares utilizados como sedes de los festejos por el Día Nacional del Afroargentino/a y la Cultura Afro en Argentina, el cual se conmemora desde la sanción de la ley en 2013 por tratarse de la fecha conmemorativa más importante que reúne al colectivo (aunque por disensos internos algunas agrupaciones decidan no participar de los festejos centrales) a partir de la decisión estatal de marcar en el calendario un día para recordar la presencia afrodescendiente en el país. Se trata principalmente de espacios estatales, como el edificio anexo de la cámara de Diputados y del Senado de la 
Nación, el complejo histórico Manzana de las Luces, la Legislatura de la ciudad de Buenos Aires, algunas universidades nacionales, entre otros, y de espacios públicos como el Parque Lezama o el centro histórico de la ciudad. La habilitación para realizar encuentros en estos lugares depende de la tramitación que realizan los dirigentes asociativos así como también de las relaciones ("contactos", según uno de los líderes) que establecen con funcionarios de diversas áreas nacionales y municipales, en particular, cultura y derechos humanos (8).

En la mayoría se han desarrollado acontecimientos históricos fundacionales para la nación y, en la actualidad, guardan una gran significación simbólica como materializaciones del pasado oficial y del saber público. Por ejemplo, el complejo histórico Manzana de las Luces, ubicado en el centro histórico de la ciudad, fue ocupado desde el siglo XVII por los jesuitas, y se caracteriza por la presencia de una red de túneles subterráneos construidos entre los siglos XVII y XVIII. Ha albergado diferentes instituciones políticas, educativas y religiosas de gran relevancia histórica y cultural. Allí se erigió la iglesia más antigua de la ciudad y el tradicional Colegio Nacional Buenos Aires, así como el primer teatro y el primer museo. Su sala de representantes fundada en 1822 ha sido el escenario donde juraron los primeros presidentes durante el siglo XIX. El edificio luego funcionó como Concejo Deliberante de la ciudad hasta que se trasladó al actual Palacio de la Legislatura. Precisamente esa sala es la que albergó las diversas actividades desarrolladas durante la conmemoración del Día del Afroargentino en 2013 y especialmente durante 2016, a través de la realización de mesas de trabajo y debate.

Por su parte, el edificio de la Legislatura porteña y el del Congreso Nacional funcionan como sedes del poder legislativo, a nivel municipal, como nacional y son representativos de la República. El palacio de la Legislatura comenzó a funcionar en la década de 1930 y ha sido sede de diversas reparticiones del estado particularmente durante la primera presidencia de Perón hasta que finalmente retomó su función legislativa municipal que continúa en la actualidad. Por otro lado, el Congreso Nacional alberga al poder legislativo desde su inauguración en 1906. En 1993 fue declarado "Monumento Histórico y Artístico Nacional" por constituirse, según el decreto, en un "referente de nuestra identidad cultural, por lo que se considera necesaria la preservación y presencia física de sus valores históricos y estéticos".

Otra sede de los festejos conmemorativos afro es el Parque Lezama, un espacio público con gran significación para la narrativa nacional ya que ha sido el lugar donde se realizó la primera fundación de la ciudad a fines del siglo XVI y se constituyó como centro del comercio de esclavos durante el siglo XVIII. En la actualidad alberga uno de los enclaves fundamentales para narrar la historia oficial de blanquitud, el Museo Histórico Nacional.

Resulta interesante observar cómo los relatos sobre el pasado de los afroargentinos específicamente en el área urbana de Buenos Aires, se espacializan sobre hitos a través de los 
cuales se articula la historia nacional. La introducción de las memorias negras a partir de la apropiación de estos espacios con fines conmemorativos da cuenta de un quiebre en esa construcción hegemónica que, como mencionamos arriba, se debilita frente a "otros" relatos subalternos que adquieren así carácter de verdad. De esta manera, memorias subterráneas (Pollak, 1989) recluidas en el ámbito privado logran sobrepasar esa esfera de interacción para erigirse en la arena pública y estatal logrando visibilidad y disputando nuevos sentidos. No obstante, debemos advertir que el carácter público que logra el relato sobre el pasado afrodescendiente no sobrepasa la esfera de interacción propia del colectivo, es decir, que quienes participan y recuerdan en estas conmemoraciones son los que componen y dirigen grupos y organizaciones afro, los funcionarios involucrados, académicos, y en una muy menor proporción, el público en general. Además las alianzas y conflictos entre diversos sectores de la dirigencia afro se replican y hasta profundizan en estas instancias, generando colaboraciones y acuerdos pero también escisiones y fracturas.

Por lo tanto, no resulta posible argumentar que esas significaciones sobre el pasado que circulan en estos espacios se construyen de manera armónica sino que se establecen en un escenario de luchas donde cobran relevancia los sectores de liderazgo, decisores principales sobre el contenido de ese pasado subalternizado que ahora encuentra el aval para ser re narrado. Como sostiene Massey (2005), el espacio, entendido dinámicamente como "constelación de trayectorias", es el producto de relaciones conflictivas y desiguales que lo convierten en una arena de disputa y, por lo tanto, de una necesaria tensión y negociación. Los casos aquí mencionados se ajustan a esta perspectiva que entiende al espacio como un lugar de intersecciones de historias, principalmente "la" historia nacional y los "otros" pasados que buscan un interlocutor que supere el ámbito privado y asociativo. Siendo que no existe una política estatal explícita donde el espacio se piense como lugar para representar otras memorias, se producen "ocupaciones" provisorias, temporales que requieren ser negociadas y autorizadas. En estos marcos provisorios y dinámicos se entretejen las historias para establecer "una memoria afro" autorizada para impugnar el relato oficial desde sus propios bastiones de nacionalidad donde habían sido negados e invisibilizados. Y aquí se evidencia el doble carácter que adquiere el estado en tanto objeto de interpelación: por un lado, como gestor de la inscripción de una idea de nación homogénea y armónica que excluyó a la población de origen afrodescendiente y re-produjo el racismo -y sus consecuencias en el presente- $y$, por el otro lado, como promotor de reconocimiento de derechos asumiendo la necesidad de reparaciones y cediendo espacios representativos de la narrativa nacional para que se introduzcan otros relatos olvidados. Es decir, a la vez como antagonista y aliado frente a las demandas de estos grupos subalternos. Gaztañaga, Piñeiro Carreras y Ferrero (2016) lo 
plantean en términos de "efectos y afectos" que no se resuelven de manera contradictoria sino que se reconvierten en una relación "constitutiva, de manera positiva, de las experiencias con el Estado, sus lógicas, sus agencias y sus campos de visión e invisibilización". En este caso, podríamos decir que la relación con el estado, específicamente a través de la "ocupación" de espacios autorizados, es reciente y se encuentra limitada principalmente a eventos conmemorativos, lo que impide aun una evaluación concluyente del balance entre "efectos" y "afectos". Se trata, como señala Stolen (2005) de un continuo proceso de construcción no exento de ambigüedades.

\section{Consideraciones finales}

En este trabajo hemos presentado algunos avances sobre las dinámicas entre memorias, visibilización y espacios hegemónicos y subalternos. Observamos cómo las memorias de los sujetos de origen africano en Argentina, olvidadas por el relato oficial de blanqueamiento, en los últimos años han disputado espacios de anclaje donde solo ciertas formas (hegemónicas) de herencia adquirían el carácter de verdad. La llegada de corrientes multiculturalistas ejerciendo presión sobre los estados nacionales ha significado una apertura y democratización de estos espacios. Sin embargo, debemos reconocer que aun existen restricciones. El colectivo afro, mediante la gestión de sus líderes, solo accede a determinados espacios estatales y públicos que se habilitan provisoriamente mientras otros aun permanecen vedados o resultan esquivos. Podríamos pensar entonces los espacios cedidos y negociados por el estado como lugares epistémicos autorizados donde se establecen marcos alternativos para la interpretación del pasado (Ramos, 2017).

Por lo tanto, observamos cómo "lugares de amnesia" (hacia la población de origen africano) se reconvierten en un "lugares de memoria" (Candau, 2001) de esos otros racializados habilitando, aunque de manera acotada y paulatina, el reconocimiento de su presencia en la historia nacional y de su contribución demográfica y cultural.

\section{Notas}

(1) Alejandro Frigerio (2008) se refiere esta clasificación como "negros" con comillas y negros sin comillas.

(2) Véanse, por ejemplo, Restrepo (2008), Frigerio y Lamborghini (2011) y Lamborghini, Geler y Guzmán (2017).

(3) Retomando la expresión de Hanchard (2008). 
(4) Entre las primeras podemos mencionar la Asociación caboverdeana de Socorros Mutuos de Dock Sud fundada en las primeras décadas del siglo XX y la más reciente Asociación de Residentes Senegaleses en Argentina (ARSA), entre las segundas se encuentran Afro Xangó, Diáspora Africana de la Argentina (DIAFAR), África y su Diáspora, Todos con Mandela, entre otras.

(5) Sin embargo, esto no significa negar la presencia afro en el ámbito de los museos, que generalmente adquiere el carácter de muestras temporarias.

(6) En los últimos meses, la sede del Movimiento Afrocultural situada en el barrio de San Telmo fue clausurada por disposición del gobierno municipal. Allí se realizaban actividades artísticas y culturales mediante cursos, talleres, exposiciones, presentaciones, etcétera.

(7) Más precisamente la Asociación cultural y deportiva Caboverdeana de Ensenada y la Unión Caboverdeana de Socorros Mutuos de Dock Sud (Avellaneda).

(8) Recordemos asimismo que la mencionada Ley 26582 del Día Nacional del Afroargentino/a y de la Cultura Afro en Argentina insta tanto al Ministerio de Educación como al de Cultura a realizar las acciones pertinentes destinadas a conmemorar la fecha en los establecimientos educativos y a promover la cultura afrodescendiente en diversos ámbitos (particularmente estatales y públicos).

\section{Bibliografía}

Alonso, A. M. (1994). The Politics of Space, Time and Substance: State Formation, Nationalism and Ethnicity. Annual Review of Anthropology, 23, pp. 379-405.

Annecchiarico, M. (2018). El patrimonio cultural afroargentino: un análisis del programa "ruta del esclavo" UNESCO en Argentina. Revista del Museo de Antropología, 11(1), pp. $229-240$.

Candau, J. (2001). Memoria e Identidad. Buenos Aires: Ediciones del Sol.

Draper, S. (2011). De cárceles y museos. Alas, itinerarios artísticos y encuadres de temporalidades. Revista Contemporánea Historia y Problemas del Siglo XX, 2(2), pp. 183-201.

Frigerio, A. (2008). De la desaparición de los negros a la reaparición de los afrodescendientes: comprendiendo la política de las identidades negras, las clasificaciones raciales y de su estudio en la Argentina. En Lechini, G. (comp.). Los estudios afroamericanos y africanos en América Latina: herencia, presencia y visiones del otro. Córdoba-Buenos Aires: Ferreyra Editor-CLACSO.

Frigerio, A. y Lamborghini, E. (2011). Los afroargentinos: formas de comunalización, creación de identidades colectivas y resistencia cultural y política. En Enghel, M. (ed.). Aportes para el desarrollo humano en Argentina 2011 (pp. 1-51). Buenos Aires: PNUD.

Geler, L. (2010). Andares negros, caminos blancos. Afroporteños, Estado y nación Argentina a fines del siglo XIX. Rosario: Prohistoria. 
Geler, L. (2012). Afrolatinoamericanas... una experiencia de subversión estereotípica en el Museo de la Mujer de Buenos Aires. Horizontes Antropológicos, 18(38), pp. 343-372.

Hanchard, M. (2008). Black memory versus state memory: notes toward a method. Small axe. A Caribbean Journal of Criticism, 26, pp. 45-62.

Jelin, E. (2002). Los trabajos de la memoria. Madrid: Siglo XXI Editores.

Lamborghini, E.; Geler, L. y Guzmán, F. (2017). Los estudios afrodescendientes en

Argentina: nuevas perspectivas y desafíos en un país «sin razas». Tabula Rasa, 27, juliodiciembre, pp. 67-101.

Monkevicius, P. (2015). Reparar algo de esta maldita historia: Memorias del pasado negro desde la narrativa estatal en Argentina. Revista Estudios Sociales, 53, julio-septiembre, pp. 112-123.

Organización de las Naciones Unidas para la Educación, la Ciencia y la Cultura (UNESCO) (2010). La Ruta del esclavo en Argentina, Paraguay y Uruguay. Recuperado de http://unesdoc.unesco.org/images/0019/001906/190690s.pdf

Pollak, M. (1989). Memória, esqueçimento, silencio. Estudos Históricos, 2(3), pp. 3-15.

Pollak, M. (1992). Memória e Identidade social. Estudos Históricos, 5(10), Rio de Janeiro, pp. 200-212.

Ramos, A. (2017). Cuando la memoria es un proyecto de restauración: el potencial relacional y oposicional de conectar experiencias. En Bello, A.; González, Y.; Rubilar, P. y Ruiz, O. (eds.). Historias y memorias. Diálogos desde una perspectiva interdisciplinaria (pp. 3851). Temuco: Universidad de la Frontera.

Restrepo, E. (2008). Multiculturalismo, gubernamentalidad, resistencia. En Almario, O. y Ruíz, M. (eds.). El giro hermenéutico de las ciencias sociales y humanas (pp. 35-48). Medellín: Universidad Nacional.

Segato, R. L. (2007). La Nación y sus Otros. Raza, etnicidad y diversidad religiosa en tiempos de Políticas de la Identidad. Buenos Aires: Prometeo Libros.

Stolen, K. A. (2005). Contradictory Notions of the State: Returned Refugees in Guatemala. En Krohn-Hansen, C. y Nustad, K. G. (Eds.). State Formation. Anthropological perspectives. London, Pluto Press. 